\title{
Implementation of a patient blood management program in an Australian private hospital orthopedic unit
}

This article was published in the following Dove Press journal: Journal of Blood Medicine

\author{
Paul N Morgan' \\ Patrick L Coleman ${ }^{2}$ \\ Cintia Mayel \\ Martinez-Garduno 3 \\ Anoja W Gunaratne ${ }^{3}$ \\ Elizabeth Mclnnes ${ }^{3}$ \\ Sandy Middleton ${ }^{3}$
}

'Quality Improvement Unit, The Mater Private Hospital (Sydney), St.Vincent's Health Australia, North Sydney, NSW, Australia; ${ }^{2}$ Dale Street Medical Specialists Pty Ltd, Brookvale, NSW, Australia; ${ }^{3}$ Nursing Research Institute, St Vincent's Health Australia (Sydney) and the Australian Catholic University School of Nursing, Midwifery and Paramedicine, Australian Catholic University, Sydney, NSW, Australia
Correspondence: Sandy Middleton Nursing Research Institute, St Vincent's Health Australia (Sydney) and Australian Catholic University, Executive Suite, Level 5 DeLacy Building, St Vincent's Hospital, Victoria Road, Darlinghurst 2010, NSW, Australia

Tel +61283823790

Fax +6I 283823792

Email sandy.middleton@acu.edu.au
Background: Preoperative anemia in surgical patients has been linked to increased rates of allogeneic blood transfusion (ABT) and associated adverse patient outcomes such as prolonged ventilation in intensive care, increased length of hospital stay, and infections. We conducted a multifaceted implementation for orthopedic surgeons to improve preoperative patient assessment of anemia and iron deficiency to reduce perioperative blood transfusions.

Materials and methods: Using a before-and-after study design of independent samples, we recruited a convenience sample of surgeons who performed primary total hip arthroplasty at 1 Australian private hospital. Our implementation intervention consisted of: executive support, interactive education, and peer-to-peer support to encourage adherence to the National Blood Authority's Patient Blood Management Program (PBMP) guidelines. We also used monthly reminders, e-learning access, and posters. Pre and post medical record audits evaluated preoperative blood tests, preoperative anemia, and number of blood units transfused between day of surgery until discharge. The primary outcome was an increase in the proportion of patients with preoperative blood tests undertaken prior to total hip arthroplasty surgery as recommended by the PBMP guidelines.

Results: Audits from 239 pre- and 263 postimplementation patients from 3 surgeons were conducted. Our primary outcome showed a significantly increased proportion of patients who had all the required preoperative tests postimplementation ( $0 \%$ to $94.6 \% ; P<0.0001)$. Administration of ABT significantly decreased (pre: $9.2 \%, \mathrm{n}=22$; post: $2.3 \%, \mathrm{n}=6 ; P=0.001$ ) as well as the standard 2 blood units transfused (pre: $73 \%, \mathrm{n}=16$; post: $17 \%, \mathrm{n}=1 ; P=0.022$ ). The time between preoperative tests and day of surgery increased from 16 to 20 days $(P<0.0001)$, allowing more time for physician's review of test results.

Conclusion: Our results demonstrated successful implementation of a targeted PBMP to improve preoperative assessment to diagnose and treat anemia and/or iron deficiency prior to orthopedic surgery. This avoided unnecessary ABT and therefore mitigated potential risk to the patient.

Keywords: anemia, allogeneic blood transfusion, iron deficiency, patient blood management, clinician behavior change, implementation research

\section{Introduction}

Preoperative anemia (hemoglobin [Hb] level of $<130 \mathrm{~g} / \mathrm{L}$ in men and $<120 \mathrm{~g} / \mathrm{L}$ in women $)^{1,2}$ is present in approximately $30 \%$ of noncardiac surgical patients. ${ }^{3}$ It is associated with increased allogeneic blood transfusion (ABT) rates, prolonged ventilation in intensive care, increased length of hospital stay, and infection..$^{3-8}$ The prevalence of preoperative anemia increases with age, ${ }^{9}$ contributing to significant morbidity and poor 
functional outcomes for older surgical patients in particular. ${ }^{6}$ Absolute or functional iron deficiency (ferritin level of $<100$ $\mu \mathrm{g} / \mathrm{L}$ or between $100 \mu \mathrm{g} / \mathrm{L}$ and $299 \mu \mathrm{g} / \mathrm{L}$ if the transferrin saturation is $<20 \%)^{10-12}$ and/or chronic inflammation are the most common causes of preoperative anemia. ${ }^{13}$

There is a plethora of literature that describes the incidence of anemia in preoperative surgical patients as well as the link between anemia, ABT, and adverse outcomes. ${ }^{4,5,7,14}$ Current transfusion practices include liberal or restrictive strategies based on thresholds of hemoglobin of $10 \mathrm{~g} / \mathrm{dL}$ or $8 \mathrm{~g} / \mathrm{dL}$, respectively. Liberal strategies have not been found to be superior to restrictive strategies, ${ }^{15-17}$ and some have shown worse patient outcomes, such as cardiac events, pneumonia, thromboembolism, and infections. ${ }^{18,19}$ Therefore, restrictive strategies have been the recommended approach when a blood transfusion is necessary to treat anemia, and as a conservative measure in the use and management of blood products.

The need to conserve blood and reduce waste has been driven by the increasing aging population, cost of "fresh" blood products, and adverse events associated with transfusions. ${ }^{8}$ In 2012 in Australia, the National Safety and Quality Health Service Standards were released. ${ }^{20}$ Standard 7 (Blood and Blood Products) specifically advocated for a safe and efficient use of blood products as a scarce resource. In addition, the new Australian Patient Blood Management (PBM) Guidelines (Module 2: Perioperative) was also published in 2012 containing 22 evidence-based recommendations and 20 practice points supporting the new standard of care to identify, evaluate, and manage preoperative anemia. ${ }^{21}$ The recommendation of the $\mathrm{PBM}$ guidelines is to perform preoperative tests comprised of: a full blood count, full iron studies (including ferritin), C-reactive protein, and renal function studies (including urea, creatinine, and electrolytes). These tests form the baseline assessment for perioperative care in which abnormal blood results should encourage physicians' review and treatment in the case of anemia, iron deficiency, and renal impairment.

The impetus for implementing a Patient Blood Management Program (PBMP) in our study was contributed to by 2 additional issues. First, a 2013 hospital-wide accreditation recommended that patients with low hemoglobin should be identified earlier and managed appropriately. Second, a 2012 retrospective medical record audit of primary total hip arthroplasty patients $(n=383)$ conducted between July and December 2011 indicated $21 \%(n=79)$ of patients received an ABT, of whom $35 \%(n=28)$ of the 79 patients were clinically anemic preoperatively resulting in $87 \%(n=69)$ of patients with 2 or more units of ABT. The argument for a PBMP is compelling and is advantageous for patients and hospitals alike. ${ }^{22}$ However, the effectiveness of achieving a change in long-standing practices involves changing perception and long-held behavior by clinicians. ${ }^{23}$ Our implementation at an Australian private hospital aimed to improve adherence of orthopedic surgeons to the PBM guidelines to evaluate and manage preoperative anemia 0-28 days prior to surgery, thereby increasing the proportion of patients with a complete set of preoperative tests prior to total hip arthroplasty surgery.

\section{Materials and methods}

Using a before-and-after design with independent samples, this study was conducted at 1 private metropolitan hospital in Sydney, Australia. This hospital was ideally placed to adopt a PBMP as it was a center that performed in excess of 2,000 total joint arthroplasties per year.

\section{Sampling and recruitment}

Eligible surgeons were those who performed $>100$ primary unilateral total hip arthroplasties each year as they were regarded to represent the patient population due to their high volume of surgical patients. Eligible surgeons and their usual anesthetists were invited by e-mail to attend a 1 hour study launch and education session presented by a specialist physician and the principal investigator. The launch outlined key messages of the PBMP (Box 1) and was convened by a specialist nephrologist with a special interest in the PBMP and was co-hosted by the Hospital Chief Executive. Following this presentation, the surgeons were visited in their consulting rooms by the principal investigator who provided the information sheet and asked for their signed consent to participate in the study.

The medical records of patients who had undergone a primary unilateral total hip arthroplasty procedure under one of the eligible participating surgeons were included. Medical records of patients who had undergone emergency surgery, bilateral or revision surgery, and those who had previously had surgery on the other hip during our preimplementation phase were excluded from the study. Patient consent was not required as this retrospective audit was considered to be part of standard hospital reporting practices. Ethical approval was obtained from St Vincent's Hospital, Darlinghurst Human Research Ethics Committee.

\section{Intervention}

The intervention was conducted from October 2014 until June 2015 (Box 2) and entailed the following: 1) executive 
Box I National Blood Authority, Australia, Patient Blood Management Guidelines: Module 2 - Perioperative 2012

Preoperative phase: All patients to have preoperative full blood count to examine hemoglobin levels, full iron tests (including ferritin and transferrin saturation), C-reactive protein, and renal function tests (urea and creatinine) added to their standard preoperative blood tests up to 28 days preoperatively.

Anemia (hemoglobin level of $<130 \mathrm{~g} / \mathrm{L}$ in men and $<120 \mathrm{~g} / \mathrm{L}$ in women) and low iron stores (ferritin level of $<100 \mu \mathrm{g} / \mathrm{L}$ ) to be treated with iron replacement prior to surgery (either oral iron in divided daily doses, or intravenous iron if oral iron not tolerated or effective or where rapid iron repletion is required ie, $<2$ months to nondeferrable surgery) as indicated by the National Blood Authority's preoperative algorithm.

As serum ferritin is an acute-phase reactant, it is important to examine both ferritin and transferrin saturation levels to determine the level of iron stores.

Postoperative phase: Patients are not to receive a blood transfusion when the hemoglobin level is $\geq 100 \mathrm{~g} / \mathrm{L}$ in the postoperative period from day of surgery until discharge on day 5-7 of the acute postoperative period.

Patients with postoperative anemia should be assessed based on the patient's clinical status and not on a hemoglobin 'trigger' alone. If a transfusion is deemed necessary, then I unit of blood is to be administered and the patient reassessed to examine response prior to further transfusion.

Note: Data from the National Blood Authority. ${ }^{21}$

\section{Box 2 PBMP implementation}

\section{Executive support}

The Chief Executive Officer of the hospital opened the project launch.

\section{Interactive education}

A specialist physician and the CEO of the hospital launched the project and presented the key PBMP messages to surgeons during a 30-minute presentation.

Orthopedic ward nurses and pre-admission clinic nurses were also informed of the implementation project and attended a single I5-minute educational session outlining PBM aims and outcome measures. Nursing education was supported by Blood Safe e-learning module - Patient Blood Management located on the hospital's intranet.

\section{Peer to peer support}

Specialist physician was available by telephone call or email to provide expert clinical advice concerning blood results and treatment.

Principal investigator made daily visits to pre-admission staff to encourage interpretation of blood results emphasising anemia and iron deficiency markers and encouragement to contact the relevant surgeon.

\section{Email and poster reminders}

Official National Blood Authority posters were placed in the stairwell and treatment rooms. These posters were changed monthly and communicated key messages such as single unit transfusion and dispelling myths about blood safety, improved healing and no associated cost with blood transfusion.

Monthly short targeted emails were sent to participating surgeons to remind them of the key points from the launch (Box 3 ), guidelines and relevant articles.

\section{Audit feedback mechanism}

Half way through the implementation phase an audit and feedback was conducted and reported back to the surgeons.

Abbreviations: CEO, Chief Executive Officer; PBMP, Patient Blood Management Program.

support from the Chief Executive Officer of the hospital who launched the project; 2) 1 interactive education session for surgeons/anesthetists and 1 for nurses conducted by the principal investigator focusing on outlining the key messages from the PBM guidelines; 3) peer-to-peer support to surgeons via telephone by the specialist physician; 4) 1 audit and feedback conducted midway through the implementation to maintain and encourage guideline compliance; and
5) monthly e-mail reminders and relevant articles sent to participating surgeons (Box 3). Other steps of the implementation included placement of Blood Watch posters, which is a state-wide transfusion practice improvement program supported by the Department of Health. ${ }^{24}$

The implementation targeted orthopedic surgeons. However, ward and preadmission clinic nurses were also invited to attend 1 education session with the rationale that they 
Box 3 Content of monthly reminder emails

I. Blood tests including full blood count, full iron tests, C-reactive protein, electrolytes/urea/creatinine should preferably be performed at least 28 days pre-op. Please "copy" the results to the general practitioner, whatever physician is involved in the patient's care, and the hospital's preadmission clinic.

2. It is never too late - ideally iron infusions should be administered at least 3 weeks prior to surgery but may provide clinically significant benefit even if administered in the days prior to surgery.

3. Consider referral to the preadmission clinic at least 4 weeks pre-op whenever possible.

4. Patients with stable cardiovascular disease do not necessarily need to have their hemoglobin "topped up" above $80 \mathrm{~g} / \mathrm{L}$. In fact, they may benefit more from an iron infusion if clinically indicated.

5. In the rare instances where a blood transfusion is considered absolutely necessary, transfuse a single unit and repeat the full blood count.

could guide, influence, and prompt surgeon and/or anesthetist compliance with guidelines by instigating preoperative iron replacement when necessary. While anesthetists also attended the initial education session, there was no further face-to-face contact with anesthetists.

\section{Data collection}

Retrospective audits of medical records from patients of consenting orthopedic surgeons were performed between July to December 2012 and July to December 2015 for the preimplementation and postimplementation audit, respectively. Patient names were obtained from preadmission clinic. Both medical record audits used identical tools and methods and were collected by the primary researcher. Audit data provided to surgeons were deidentified and aggregated.

\section{Outcome measures}

The primary outcome measure was the number of patients who 0-28 days prior to total hip arthroplasty surgery had all of the following preoperative blood tests: 1) full blood count, 2) full iron studies, including ferritin and transferrin saturation, 3) C-reactive protein, 4) renal function studies, including urea, creatinine, and electrolytes.

Secondary outcome measures were 1) the number of ABTs administered between the day of surgery and postoperative day 7 (or day of discharge - whichever came first), 2) the time between ordering the preoperative tests and day of surgery (in days), 3) the level of anemia as defined by the World Health Organization definition (hemoglobin $<130 \mathrm{~g} / \mathrm{L}$ in men and $<120 \mathrm{~g} / \mathrm{L}$ in women), 4) iron deficiency defined as a ferritin $<100 \mu \mathrm{g}$ per liter or between 100 and $299 \mu \mathrm{g}$ per liter if the transferrin saturation is $<20 \%$ in the $0-28$ days prior to day of surgery, 5) the number of preoperative iron infusions related to low ferritin and transferrin saturation, and 6) the administration of tranexamic acid (antifibrinolytic proven to reduce a patient's perioperative blood loss).

\section{Instrument}

The following data were collected using a piloted form: 1) patient characteristics; 2) laboratory results; 3 ) clinical treatment; 4) surgery details; 5) and postoperative treatment. In the patient characteristics section age, gender, admission, and discharge dates were recorded. Preoperative laboratory results were obtained from both the medical records and access to the online pathology service. The number of days between the preoperative tests and the booked surgery date was recorded. The preoperative tests comprised: full blood count, full iron studies (including ferritin and transferrin saturation), C-reactive protein, and renal function studies (including urea, creatinine, and electrolytes count). In the clinical treatment section of the instrument, we recorded the administration of a preoperative iron infusion. Surgery details collected were surgery date, the use of tranexamic acid (Yes/ No), and the American Society of Anesthesiologists score (ASA) completed by the anesthetist prior to induction. ${ }^{25}$ Finally, the postoperative treatment data collected included the number of ABT units and, where relevant, the postoperative day of transfusion.

\section{Data analysis}

Data were analyzed using SPSS version (IBM SPSS Statistics 23, IBM Corporation, Armonk, NY, USA). The proportion of patients who had all 4 preoperative blood tests performed was calculated. The categorical and continuous data were summarized as descriptive statistics. Pre- and postimplementation differences for patient characteristics, preoperative blood tests, anemic patients with $\mathrm{ABT}$ and use of tranexamic acid were examined using $\chi^{2}$ tests or Fisher's exact test as appropriate. Independent sample $t$-test was used to examine mean differences of time between the ordering day of the preoperative tests and the day of surgery in the pre- and postimplementation groups. The $P$-value for the statistical significance was set at $<0.05$. 


\section{Results}

All 3 eligible orthopedic surgeons agreed to participate in the study. A total of 239 medical records of patients undergoing primary total hip arthroplasty were audited for the preimplementation phase and 263 for the postimplementation phase. All patients' medical records from participating surgeons in the preimplementation group met the inclusion criteria. In the postimplementation phase, there were 2 patients who were excluded: 1 was an emergency fracture and the other patient had a unilateral hip and knee replacement concurrently. There were $64 \%(n=154)$ females in the preimplementation phase and $58 \%(n=151)$ in the postimplementation phase. The most common age group was $61-80$ years old, with $61 \%(n=145)$ in the preimplementation and $70 \%,(n=183)$ in the postimplementation phase (Table 1). The overall health status of patients was inferred by the ASA score. The ASA showed that the highest rating assessment was ASA 2 (pre: $47 \%, \mathrm{n}=113$; post: $40 \%, \mathrm{n}=105 ; P=0.19)$ indicating that most patients in both groups were relatively healthy. The only significant difference between groups was for the ASA
3 score (ie, severe systemic disease), but this was seen only in $11 \%$ of patients from the preimplementation and $20 \%$ of patients from the postimplementation $(P=0.003$; Table 1$)$.

\section{Primary outcome}

There was a significant increase in the number of patients who 0-28 days prior to total hip arthroplasty surgery had all preoperative tests performed following our intervention (95\%; $\mathrm{n}=247, P<0.0001)$, compared to none in the preimplementation group (Table 2). Of these preoperative tests, over $98 \%$ of patients in both pre- and postimplementation group had a full blood count and renal function studies performed. However, significant increases were observed from pre- $(n=1,0.4 \%)$ to postimplementation $(n=254$, $97 \%$ ) in the number of patients who had full iron studies $(P<0.0001)$ and a $C$-reactive protein test (pre: $n=132$, 55\%; post: $\mathrm{n}=245,94 \% ; P<0.0001$ ). Time (days) between the preoperative tests and the date of surgery significantly increased from 16 to 20 days following the implementation $(P<0.0001$, Table 2).

Table I Patient demographics

\begin{tabular}{|c|c|c|c|}
\hline Demographics & $\begin{array}{l}\text { Preimplementation } \\
(\mathrm{n}=239) \mathrm{n}(\%)\end{array}$ & $\begin{array}{l}\text { Postimplementation } \\
(n=261) n(\%)\end{array}$ & P-value* \\
\hline \multicolumn{4}{|l|}{ Gender } \\
\hline Female & $154(64)$ & $|5|(58)$ & 0.132 \\
\hline Male & $85(36)$ & $110(42)$ & \\
\hline \multicolumn{4}{|l|}{ Age (years) } \\
\hline $0-40$ & $3(1.2)$ & $5(1.9)$ & 0.402 \\
\hline $4 I-60$ & $72(30)$ & $50(19)$ & \\
\hline $61-80$ & $145(61)$ & $183(70)$ & \\
\hline $81+$ & $19(7.9)$ & $23(8.8)$ & \\
\hline \multicolumn{4}{|l|}{$\mathrm{ASA}^{\mathrm{a}}$} \\
\hline Healthy person & $47(20)$ & $35(13)$ & 0.87 \\
\hline Mild systemic disease & $113(47)$ & $105(40)$ & 0.19 \\
\hline Severe systemic disease & $26(11)$ & $51(20)$ & $0.003 *$ \\
\hline Severe systemic disease that is a constant threat to life & 0 & $3(1.1)$ & $0.25^{b}$ \\
\hline Not recorded & $53(22)$ & $67(26)$ & \\
\hline
\end{tabular}

Notes: aPhysical status system by ASA, ' Fisher's exact test, $* P$-value significant $<0.05$. Abbreviation: ASA, American Society of Anesthesiologists.

Table 2 Patient's preoperative tests and time completed

\begin{tabular}{|c|c|c|c|}
\hline Preoperative tests & $\begin{array}{l}\text { Preimplementation } \\
(n=239) \text { n (\%) }\end{array}$ & $\begin{array}{l}\text { Postimplementation } \\
(n=26 I) n(\%)\end{array}$ & P-value* \\
\hline Full blood count & $238(99.5)$ & $260(99.6)$ & 0.999 \\
\hline Full iron studies (ferritin and transferrin saturation) & I (0.4) & $254(97)$ & $<0.0001 *$ \\
\hline C-reactive protein & $132(55)$ & $245(94)$ & $<0.000 I^{*}$ \\
\hline Renal function studies (urea, creatinine, and electrolytes) & $238(99.5)$ & $258(98.8)$ & $0.625^{\mathrm{a}}$ \\
\hline All above preoperative tests completed & 0 & $247(95)$ & $<0.000 I^{*}$ \\
\hline $\begin{array}{l}\text { Time (days) preoperative blood sample obtained to day of } \\
\text { surgery (mean) }\end{array}$ & 16 (days) & 20 (days) & $<0.000 I^{*}$ \\
\hline
\end{tabular}

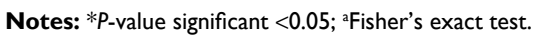




\section{Secondary outcomes}

The levels of preoperative anemia were not significantly different between the pre- and postimplementation group ( $P=0.224$ ) (Table 3 ). However, there was a significant decrease of ABT postoperatively (pre: $9.2 \%, \mathrm{n}=22$ and post: $2.3 \%, \mathrm{n}=6 ; P<0.001)$. Of those patients who received an ABT, there was a significant increase in the number of patients receiving only a single unit of blood as per the guidelines following the implementation $(P<0.003)$. Iron infusions were not given to any of the patients in the preimplementation group compared to $4.5 \%(\mathrm{n}=12)$ in the postimplementation group prior to surgery $(P=0.001)$. The use of tranexamic acid improved significantly following implementation (pre: $65 \%$, $\mathrm{n}=155$; post: $93 \%, \mathrm{n}=242 ; P<0.0001)$ (Table 3$)$.

\section{Discussion}

Our results showed that significantly more patients were treated according to the PBMP guidelines in undergoing all the required preoperative blood tests following our implementation strategy. The postimplementation group received a more rigorous preoperative assessment, resulting in increased administration of iron infusions for severely iron deficient patients and therefore avoiding the habitual approach of unnecessary ABT. ${ }^{26,27}$ In addition, there was a significant increase in the rates of single-unit transfusions and a corresponding decrease in 2-unit transfusions when compared to the preimplementation group. Single-unit transfusion practice is an integral component of a PBMP, as it decreases waste and risk associated with transfusions from multiple donors. In comparison, transfusions using 2 units of blood have often been a default decision without supportive empirical data, noncognizant of the risks versus the benefit. ${ }^{24}$ In addition, the significant increase postimplementation in the use of antifibrinolytic agents such as tranexamic acid may have also contributed to the decrease in ABT due to their effects of reduction in blood loss and higher postoperative hemoglobin. ${ }^{28}$ These results are notable despite the significant number of patients with an ASA 3 score (severe systemic disease) in the postimplementation group compared to the preimplementation group, demonstrating the benefits of changing clinician behavior when treating patients with known comorbidities.

For those patients identified as anemic and/or iron deficient, iron infusions were advocated instead of iron taken orally, as per the guidelines for those whose surgery is to commence within 2 months. Iron infusions are a more effective treatment for iron deficiency anemia because they correct levels more quickly than oral iron. ${ }^{10,29,30}$ The iron infusion can take effect between 2 and 6 weeks compared to oral intake that can require on average 6 weeks. ${ }^{31}$ Consequently, as our primary outcome was only relevant to patients $0-28$ days prior to surgery, we did not collect data on the number of patients taking oral iron. Patients in the preimplementation group could not be identified as iron deficient due to lack of routine iron studies testing undertaken at that time. Therefore, none of the preimplementation group patients received an infusion

Table 3 Patient preoperative diagnosis of anemia and iron deficiency and postoperative management

\begin{tabular}{|c|c|c|c|}
\hline & $\begin{array}{l}\text { Preimplementation } \\
(n=239) n(\%)\end{array}$ & $\begin{array}{l}\text { Postimplementation } \\
(n=261) \text { n (\%) }\end{array}$ & $P$-value* \\
\hline \multicolumn{4}{|l|}{ Preoperative anemia and iron deficiency ${ }^{\mathrm{a}}$} \\
\hline Patients with anemia (full blood count - hemoglobin) & $12(5.0)$ & $20(7.6)$ & 0.224 \\
\hline Patients with iron deficiency (full iron studies) & Not known & $105(40)$ & \\
\hline $\begin{array}{l}\text { Patients with anemia and iron deficiency (full blood count } \\
\text { and full iron studies) }\end{array}$ & Not known & $13(4.9)$ & \\
\hline \multicolumn{4}{|l|}{ Iron infusion and intraoperative tranexamic acid injection } \\
\hline Received iron infusion preoperatively & 0 & $12(4.5)$ & $0.00 I^{*}$ \\
\hline Tranexamic acid used, intraoperatively/postoperatively & $155(65)$ & $242(93)$ & $<0.000 I^{*}$ \\
\hline \multicolumn{4}{|l|}{ Postoperative ABT } \\
\hline Number of patients who received an $A B T$ & $22(9.2)$ & $6(2.3)$ & $0.001 *$ \\
\hline I blood unit & $3 / 22(14)$ & $5 / 6(83)$ & $0.003^{\mathrm{a}}$ \\
\hline 2 blood units & $16 / 22(73)$ & $1 / 6(17)$ & $0.022^{\mathrm{a}}$ \\
\hline $3-5$ blood units & $3 / 22(14)$ & $0 / 6$ & $0.999^{a}$ \\
\hline $\begin{array}{l}\text { Number of preoperative anemic patients (full blood count - } \\
\text { hemoglobin) transfused }\end{array}$ & $7 / 12(58)$ & $5 / 20(25)$ & 0.059 \\
\hline $\begin{array}{l}\text { Number of patients with both preoperative anemia and iron } \\
\text { deficiency transfused, as \% of total patients transfused }\end{array}$ & Not known & $4(67)$ & $N / A$ \\
\hline
\end{tabular}

Notes: $* P$-value significant $<0.05$, a Fisher's exact test. Anemia defined as hemoglobin level of $<130 \mathrm{~g} / \mathrm{L}$ in men and $<120 \mathrm{~g} / \mathrm{L}$ in women; iron deficiency defined as ferritin level of $<100 \mu \mathrm{g} / \mathrm{L}^{21}$

Abbreviations: $A B T$, allogenic blood transfusion; N/A, not applicable. 
prior to surgery. That a significant increase of 4 days between the preoperative blood tests to day of surgery was observed is of note. This increase postimplementation allowed more time for further assessment of patients for anemia and/or iron deficiency and for treatment with iron infusion prior to surgery. It is possible some of these infusions also may have been ordered by the anesthetist (and not necessarily the surgeon) at the time of the preadmission clinic.

A limitation of our study is the time frame between audits. Prior to the PBM guidelines release at the end of 2012, awareness of blood management among hospital clinicians was poor. Therefore, the decision for our study was to use the final 6 months of 2012 with the rationale that staff would be relatively untainted from the release of the PBM guidelines. This resulted in the time frame gap that is observed between the medical record audits for the preand postimplementation. We also did not collect data on the cost-effectiveness of our intervention, which was beyond the scope of our study.

The inherent challenges of implementation in a private hospital setting are of note. Australia has a growing private hospital sector operating alongside public hospitals. Private hospitals allow the medical practitioners more autonomy. ${ }^{32}$ Therefore, private hospitals must balance the introduction of best practice guidelines without dictating this to medical staff. The preadmission clinic has a rapid flow of patients which discourages analytical review of pathology test results. The difficulty of obtaining a medical order in the private system and the potential for adverse side effects were contributing factors in the hesitation to prescribe an iron infusion. Although orthopedic surgeons at the hospital were aware of the advantages of meticulous surgical care and tranexamic acid use to reduce blood loss, they were less convinced about the importance of managing preoperative anemia and iron deficiency. Hence, although challenging, we successfully modified the surgeons' views that a PBMP would be beneficial for their medical reputation and better outcomes for their patients. To the best of our knowledge, this is one of the first published studies implementing the PBM guidelines in a private hospital setting in Australia.

\section{Conclusion}

Our results demonstrated that programs to implement guidelines can be built into the current processes of care and can improve patient outcomes. Our study is one of the few to provide evidence of the effectiveness of a targeted implementation to improve early assessment and preoperative management of anemia and/or iron deficiency in a private hospital setting. Other hospitals should consider replicating our intervention to better manage postoperative anemia and reduce the associated inherent risks of blood transfusions and conserving this limited resource.

\section{Acknowledgment}

The abstract of this paper was published in http://www.achs. org.au/media/103534/quality initiatives 2016 - long version web pdf as an entry for the 19th Annual ACHS Quality Improvement Awards 2016.

\section{Author contributions}

PNM coordinated and carried out the study. PNM also carried out the preimplementation and postimplementation data audits, nurse education, data collection, data entering, and the majority of the writing of the manuscript. PNM and PLC conceived the study. PLC provided medical education, expert advice, and review of the manuscript. CMMG assisted with ethics approval, statistical interpretation, and review of the manuscript. AWG provided statistical analysis and interpretation and review of the manuscript. SM participated in the design of the study and assisted with the construction and review of the manuscript. All authors contributed toward data analysis, drafting and revising the paper and agree to be accountable for all aspects of the work.

\section{Disclosure}

The authors report no conflicts of interest in this work.

\section{References}

1. World Health Organisation. Nurtitional Anaemia. Geneva: World Health Organisation; 1968.

2. World Health Organisation, United Nations Children's Fund, United Nations University. Iron Deficiency Anaemia: Assessment, Prevention, and Control. A Guide for Programme Managers. Geneva: World Health Organisation; 2001.

3. Musallam KM, Tamim HM, Richards T, et al. Preoperative anaemia and postoperative outcomes in non-cardiac surgery: a retrospective cohort study. Lancet. 2011;378(9800):1396-1407.

4. Shander A, Javidroozi M, Ozawa S, Hare G. What is really dangerous: anaemia or transfusion? Br J Anaesth. 2011;107(Suppl 1):i41-i59.

5. Kumar A. Perioperative management of anemia: limits of blood transfusion and alternatives to it. Cleve Clin J Med. 2009;76(Suppl 4): S112-S118.

6. Partridge J, Harari D, Gossage J, Dhesi J. Anaemia in the older surgical patient: a review of prevalence, causes, implications and management. $J R$ Soc Med. 2013;106(7):269-277.

7. Isbister JP, Shander A, Spahn DR, Erhard J, Farmer SL, Hofmann A. Adverse blood transfusion outcomes: establishing causation. Transfus Med Rev. 2011;25(2):89-101.

8. Leahy M, Mukhtar SA. From blood transfusion to patient blood management: a new paradigm for patient care and cost assessment of blood transfusion practice. Intern Med J. 2012;42(3):332-338.

9. Guralnik JM, Eisenstaedt RS, Ferrucci L, Klein HG, Woodman RC. Prevalence of anemia in persons 65 years and older in the United States: evidence for a high rate of unexplained anemia. Blood. 2004;104(8):2263-2268. 
10. Anker SD, Comin Colet J, Filippatos G, et al. Ferric carboxymaltose in patients with heart failure and iron deficiency. New Engl J Med. 2009;361(25):2436-2448.

11. Ponikowski P, van Veldhuisen DJ, Comin-Colet J, et al. Beneficial effects of long-term intravenous iron therapy with ferric carboxymaltose in patients with symptomatic heart failure and iron deficiency. Eur Heart J. 2015;36(11):657-668

12. Wish JB. Assessing iron status: beyond serum ferritin and transferrin saturation. Clin J Am Soc Nephrol. 2006;1(Suppl 1):S4-S8.

13. Muñoz M, García-Erce JA, Cuenca J, Bisbe E, Naveira E; AWGE (Spanish Anaemia Working Group). On the role of iron therapy for reducing allogeneic blood transfusion in orthopaedic surgery. Blood Transfus. 2012;10(1):8-22.

14. Partridge J, Harari D, Gossage J, Dhesi J. Anaemia in the older surgical patient: a review of prevalence, causes, implications and management. J R Soc Med. 2013:106(7):269-277.

15. Hébert PC, Wells G, Blajchman MA, et al. A multicenter, randomized, controlled clinical trial of transfusion requirements in critical care. New Engl J Med. 1999;340(6):409-417.

16. Hajjar LA, Vincent JL, Galas FR, et al. Transfusion requirements after cardiac surgery: the TRACS randomized controlled trial. JAMA. 2010;304(14): 1559-1567.

17. Carson JL, Terrin ML, Magaziner J, et al; FOCUS Investigators. Transfusion trigger trial for functional outcomes in cardiovascular patients undergoing surgical hip fracture repair (FOCUS). Transfusion. 2006;46(12):2192-2206.

18. Villanueva C, Colomo A, Bosch A, et al. Transfusion strategies for acute upper gastrointestinal bleeding. New Engl J Med. 2013;368(1):11-21.

19. Teng Z, Zhu Y, Liu Y, et al. Restrictive blood transfusion strategies and associated infection in orthopedic patients: a meta-analysis of 8 randomized controlled trials. Sci Rep. 2015;5:13421.

20. Australian Commission on Safety and Quality in Health Care. National Safety and Quality Health Service Standards. Sydney, Australia: ACSQHC; 2012.
21. The National Blood Authority. Patient Blood Management Guidelines: Module 2-Perioperative. Canberra, Australia: National Health Medical Research Council; 2012.

22. Spahn DR, Theusinger OM, Hofmann A. Patient blood management is a win-win: a wake-up call. Br J Anaesth. 2012;108(6):889-892.

23. Francis JJ, Tinmouth A, Stanworth SJ, et al. Using theories of behaviour to understand transfusion prescribing in three clinical contexts in two countries: development work for an implementation trial. Implement Sci. 2009;4:70.

24. Shander A, Isbister J, Gombotz H. Patient blood management: the global view. Transfusion. 2016;56(Suppl 1):S94-S102.

25. Chand M, Armstrong T, Britton G, Nash GF. How and why do we measure surgical risk? J R Soc Med. 2007;100(11):508-512.

26. Shander A, Knight K, Thurer R, Adamson J, Spence R. Prevalence and outcomes of anemia in surgery: a systematic review of the literature. Am J Med. 2004;116(Suppl 7):58S-69S.

27. Goodnough LT, Maniatis A, Earnshaw P, et al. Detection, evaluation, and management of preoperative anaemia in the elective orthopaedic surgical patient: NATA guidelines. Br J Anaesth. 2011;106(1):13-22.

28. Munoz M, García-Erce JA, Villar I, Thomas D. Blood conservation strategies in major orthopaedic surgery: efficacy, safety and European regulations. Vox Sang. 2009;96(1):1-13.

29. Khalafallah A, Dennis A, Bates J, et al. A prospective randomized, controlled trial of intravenous versus oral iron for moderate iron deficiency anaemia of pregnancy. J Intern Med. 2010;268(3):286-295.

30. Department for Health \& Ageing Government of South Australia. Intravenous iron infusions. Consumer information. Australia: Blood Safe. eLearning Australia. Available from: https://bloodsafelearning. org.au/iv-iron-tools/. Accessed April 11, 2018.

31. Muñoz M, Acheson A, Auerbach M, et al. International consensus statement on the peri-operative management of anaemia and iron deficiency. Anaesthesia. 2017;72(2):233-247.

32. Duckett SJ. Living in the parallel universe in Australia: public Medicare and private hospitals. CMAJ. 2005;173(7):745-747.
Journal of Blood Medicine

\section{Publish your work in this journal}

The Journal of Blood Medicine is an international, peer-reviewed, open access, online journal publishing laboratory, experimental and clinical aspects of all aspect pertaining to blood based medicine including but not limited to: Transfusion Medicine; Blood collection, Donor issues, Transmittable diseases, and Blood banking logistics; Immunohematology; Artificial and alternative

\section{Dovepress}

blood based therapeutics; Hematology; Biotechnology/nanotechnology of blood related medicine; Legal aspects of blood medicine; Historical perspectives. The manuscript management system is completely online and includes a very quick and fair peer-review system. Visit http://www.dovepress.com testimonials.php to read real quotes from published authors. 